\title{
Blood pressure lowering effect of scopoletin on oxidative stress-associated hypertensive rats
}

\author{
Armenia ARMENIA* (D), Rahmat HIDAYAT (D), Meiliani MEILIANI (D), Yori YULIANDRA \\ Department of Pharmacology \& Clinical Pharmacy, Faculty of Pharmacy, Andalas University, Campus Limau \\ Manis, Pauh, Padang 25163, West Sumatra, Indonesia. \\ * Corresponding Author. E-mail: armenia@phar.unand.ac.id (A.A.); Tel: +62 751-71682, Fax: +62 751-777057.
}

Received: 29 May 2018 / Revised: 12 August 2018 / Accepted: 16 August 2018

\begin{abstract}
Scopoletin is a coumarin derivative known for its antioxidant capacity. The present study was undertaken to investigate the blood pressure lowering effect of scopoletin in multiple models of hypertensive rats. To obtain animal models of hypertension, a number of 18 Wistar-Kyoto male rats were divided into two groups receiving a combination of oral prednisone and salt for 14 days (PN group, the endocrine hypertension model) while another half received the same inducers with an additional $\mathrm{N}^{\omega}$-nitro-L-arginine methyl ester (L-NAME) for 2 days (PNL group, oxidative stressassociated hypertension model). The rats were anesthetized with propofol and subdivided into 3 groups receiving control, scopoletin $10 \mathrm{mg} / \mathrm{kg}$, and tempol $100 \mu \mathrm{mol} / \mathrm{kg}$. The systolic blood pressure (SBP), diastolic blood pressure (DBP), mean arterial blood pressure (MAP) and heart rate (HR) were recorded for 120 minutes after a single dose of drug commencement. The serum concentration of nitric oxide (NO) was measured before and at the end of the experiment. The data were analyzed using two-way ANOVA followed by Tukey's HSD with 95\% confidence interval. The results showed that scopoletin decreased the SBP, DBP, and MAP of the rats significantly $(p<0.05)$ without any significant effect on the animal HR $(p>0.1)$. The concentration of NO in animals receiving scopoletin and tempol was greater as compared control, but there was no significant difference in blood NO between both hypertensive models $(p>0.1)$. The study concludes that scopoletin is effective as blood pressure lowering agent on oxidative stress-associated hypertensive rats.
\end{abstract}

KEYWORDS: scopoletin; antihypertensive; heart rate; nitric oxide; oxidative stress; L-NAME.

\section{INTRODUCTION}

Hypertension is considered the biggest sole contributor to the global burden of diseases in human and global mortality as well. The prevalence of high blood pressure continues to increase worldwide and is expected rise $10 \%$ in all regions. The high mortality from this disease is predominantly mediated through coronary heart disease and stroke [1]. Global data show that nearly one billion people have elevated blood pressure, in which two-thirds of them are in developing countries. This disease kills approximately 8 million people every year worldwide and 1.5 million in ASEAN countries [2]. The family life survey in Indonesia revealed that $70 \%$ of those living with high blood pressure were undiagnosed and left untreated. Moreover, $90 \%$ of the hypertension cases are uncontrolled [3].

Scopoletin (6-methoxy-7-hydroxycoumarin, Figure 1A) is a popular coumarin derivative that has been isolated from several plant species from different families. These include Solanaceae, Aceraceae, Brassicaceae, Compositae, Convolvulaceae, Rutaceae, Umbelliferone and many others that mostly grow in Indonesia. These plants produce scopoletin with different amount and can reach $700 \mathrm{nmol} / \mathrm{g}$ of fresh weight of the plant [4]. Following some reports on the traditional use of these plants, many studies have revealed that scopoletin exhibits some interesting pharmacological properties, ranging from anti-infectious, cytotoxicity, antiinflammatory, and those acting within the cardiovascular system [4-8]. In addition, some in vitro studies prove that scopoletin exhibits a potent antioxidant activity that makes this chemical even more potential for drug development [9-11]. Some plants' extracts that contain scopoletin have also been confirmed for their pharmacological activities in the cardiovascular system. These include vasorelaxant and hypotensive effects investigated in rats and rabbits [12-14].

How to cite this article: Armenia A, Hidayat R, Meliani M, Yuliandra Y. Blood pressure lowering effect of scopoletin on oxidative stress-associated hypertensive rats. J Res Pharm. 2019; 23(2): 249-258. 
Several antioxidant compounds that exhibit blood pressure lowering effect have been reported. Vitamin $\mathrm{C}$ and $\mathrm{E}$ are among the most well-known antioxidants that significantly lower the blood pressure [15-17]. Astaxanthin, a natural antioxidant from aquatic living organisms, can reduce the systolic and diastolic blood pressure and delay the progression of stroke [18]. Tempol, a nitroxide antioxidant used in the present study (Figure 1B), has been reported to cause rapid and dose-dependent blood pressure lowering effect when administered intravenously [19]. These scientific reports support the potency of antioxidant compounds in lowering the blood pressure in both experimental animals and hypertensive human. Hence, to study the blood pressure activity of antioxidant compounds, the use of oxidative stress animal models is suggested. These include the use of $\mathrm{NG}_{-}$nitro- 1- arginine methyl ester (L- NAME) as the pharmacological inducer to obtain oxidative stress-related hypertension [20].<smiles>COc1cc2ccc(=O)oc2cc1O</smiles>

A<smiles>CC1(C)CC(O)CC(C)(C)N1O</smiles>

B

Figure 1. Chemical structures of A) Scopoletin $\left(\mathrm{C}_{10} \mathrm{H}_{8} \mathrm{O}_{4}\right)$, 7-hydroxy-6-methoxychromen-2-one; B) Tempol $\left(\mathrm{C}_{9} \mathrm{H}_{18} \mathrm{NO}_{2}\right)$, 1- $\lambda^{1}$-oxidanyl-2,2,6,6-tetramethylpiperidin-4-ol.

Scopoletin is likely to have a great potency to lower the high blood pressure. Hence, this compound could be developed to an antihypertensive drug. However, the blood pressure lowering effect of scopoletin as a single compound has not been reported to our knowledge. This manuscript provides an overview of antihypertensive activity of scopoletin on some hypertensive models in rats.

\section{RESULTS}

In general, the blood pressure and heart rate of PNL animal were higher than those of PN animal after the hypertensive induction (Table 1). However, comparative analysis of the parameters did not show any significant different between both groups $(\mathrm{p}>0.1)$. On the other hand, the comparative effect of the treatment of scopoletin on the blood pressure and heart rate is presented in Table 2.

Table 1. Comparative effect of the hypertensive induction to blood pressures and heart rate.

\begin{tabular}{ccccc}
\hline Parameter & Animal Model & n & Mean \pm SEM & P \\
\hline \multirow{2}{*}{ SBP (mmHg) } & PN & 9 & $207.90 \pm 7.10$ & 0.160 \\
& PNL & 9 & $225.13 \pm 9.30$ & 0.191 \\
\hline \multirow{2}{*}{ DBP (mmHg) } & PN & 9 & $185.66 \pm 6.80$ & 0.202 \\
\hline \multirow{2}{*}{ MAP (mmHg) } & PNL & 9 & $200.27 \pm 8.26$ & 0.605 \\
\hline \multirow{2}{*}{ HR (bpm) } & PN & 9 & $198.02 \pm 7.88$ & $213.92 \pm 8.96$ \\
\hline
\end{tabular}

SBP: systolic blood pressure; DBP: diastolic blood pressure; MAP: mean arterial pressure; HR: heart rate; PN: group treated with prednisone $+\mathrm{NaCl}$; PNL: group treated with prednisone $+\mathrm{NaCl}+\mathrm{L}-\mathrm{NAME}$.

\subsection{Systolic (SBP) and diastolic blood pressure (DBP)}

The treatment influenced the systolic (SBP) and diastolic blood pressure (DBP) significantly $(\mathrm{p}<0.05)$. Scopoletin caused a remarkable decrease in SBP and DBP as compared with control and tempol. Comparative blood pressure lowering effect of scopoletin to SBP and DBP (Table 3) shows that the compound is superior in oxidative stress-associated hypertensive rats (PNL group). Figures 2 and 3 demonstrate the antihypertensive effect of scopoletin to SBP and DBP in both hypertensive models during 120 minutes of observation. 


\subsection{Mean Arterial Pressure (MAP)}

The treatment of scopoletin also influenced mean arterial pressure (MAP) significantly $(\mathrm{p}<0.05)$. The decrease of MAP due to scopoletin was better as compared with control and tempol. Comparative effect of scopoletin between PN and PNL group (Table 4) shows that the blood pressure lowering effect of scopoletin is better in oxidative stress-associated hypertensive rats (PNL group). The blood pressure lowering effect of scopoletin to MAP in both hypertensive models during 120 minutes of observation is demonstrated in Figure 4.

\subsection{Heart Rate (HR)}

In contrast to SBP and DBP, the treatment did not significantly influence the heart rate (HR) of the animals ( $p>0.05$ ). Although the HR fluctuated during the monitoring period, the change of the parameter was not significant (Table 3). However, the comparative effect in both groups showed that the treatment caused a significant decrease of HR in PN group, despite in small amount (Table 4). In this group, scopoletin caused the heart rate to stabilize despite other group showed dramatic change. The effect of scopoletin on HR in both hypertensive models during 120 minutes of observation is demonstrated in Figure 5.

Table 2. Average effect of the treatment to blood pressures and heart rate.

\begin{tabular}{lcccc}
\hline Doses & SBP & DBP & MAP & HR \\
\hline Control & $-4.11 \pm 1.61^{\mathrm{a}}$ & $-2.63 \pm 2.25^{\mathrm{a}}$ & $-6.59 \pm 2.25^{\mathrm{a}}$ & $1.16 \pm 2.25^{\mathrm{a}}$ \\
Scopoletin & $-19.60 \pm 1.61^{\mathrm{ab}}$ & $-19.63 \pm 2.25^{\mathrm{c}}$ & $-43.33 \pm 2.25^{\mathrm{c}}$ & $-0.21 \pm 2.25^{\mathrm{bc}}$ \\
Tempol & $-7.12 \pm 1.61^{\mathrm{a}}$ & $-9.66 \pm 2.25^{\mathrm{b}}$ & $-18.46 \pm 2.25^{\mathrm{b}}$ & $-3.39 \pm 2.25^{\mathrm{c}}$ \\
\hline
\end{tabular}

SBP: systolic blood pressure; DBP: diastolic blood pressure; MAP: mean arterial pressure; HR: heart rate; $(n=18)$.

Data are expressed as mean of percent change \pm SEM. Negative (-) values indicate the decrease of parameters.

Different superscript indicates significant difference at 95\% confidence interval (post hoc analysis by Tukey's HSD).

\subsection{Serum concentration of nitric oxide (NO)}

All doses of the treatment increased the serum concentration of nitric oxide (NO) in both groups (Figure 6). However, there was no significant difference between NO increase in PN and PNL groups due to the treatment $(p>0.1)$, despite scopoletin and tempol significantly increased NO in both PN and PNL groups compared with control $(\mathrm{p}<0.05)$. Table 5 shows the comparative effect of scopoletin on the serum concentration of $\mathrm{NO}$ in both groups.

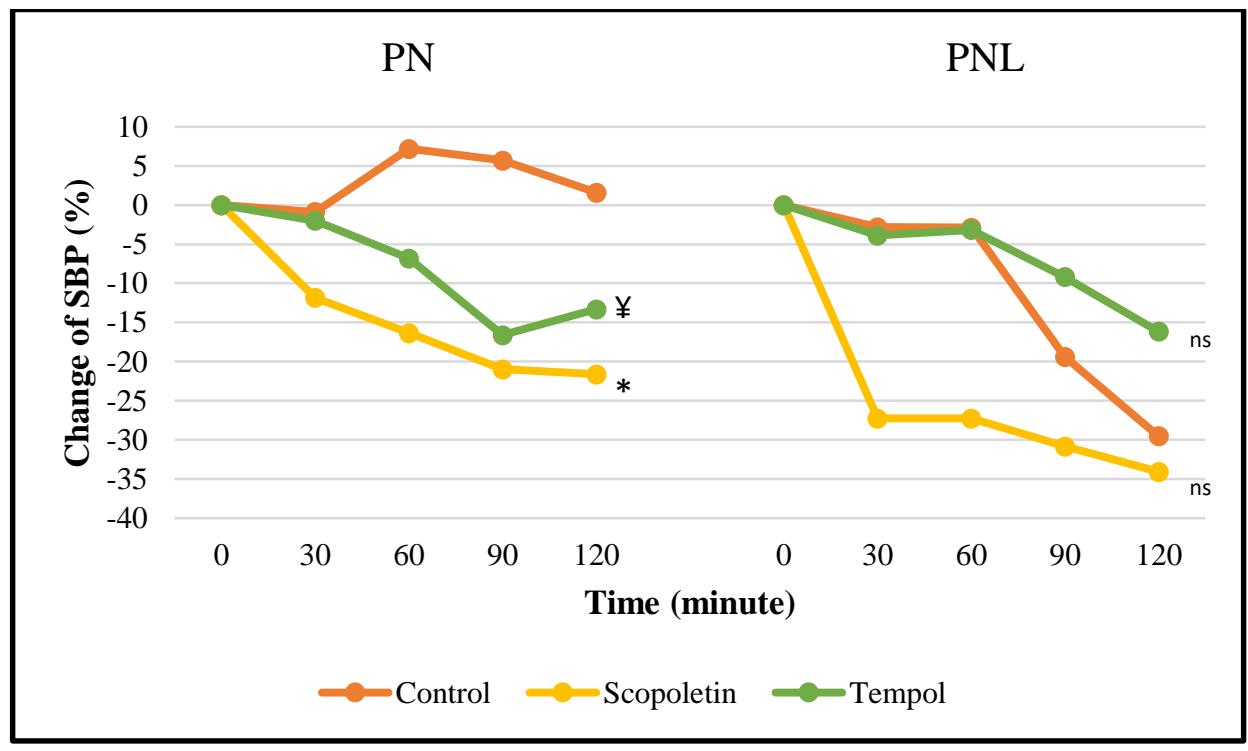

Figure 2. Comparative effect of the treatment to SBP (systolic blood pressure) on different hypertensive models during 120 minutes of observation $(\mathrm{PN}=$ group treated with prednisone $+\mathrm{NaCl}$; $\mathrm{PNL}=$ group treated with prednisone $+\mathrm{NaCl}+\mathrm{L}-\mathrm{NAME}$; data with negative $(-)$ values indicate the decrease of the parameter; ${ }^{*} \mathrm{p}<0.05, ¥ 0.05<\mathrm{p}<0.1$, and $\mathrm{ns}=$ not significant comparative to control; $\mathrm{n}=18$ ). 
Table 5. Comparative effect of the treatment to the serum concentration of nitric oxide (NO) in PN \& PNL hypertensive groups.

\begin{tabular}{lccc}
\hline \multirow{2}{*}{ Doses } & \multicolumn{2}{c}{ Percent increase of NO (\%) } & Average \\
\cline { 2 - 3 } & PN & PNL & \\
\hline Control & $11,39 \pm 0,84$ & $29,24 \pm 22,99$ & $20,31 \pm 16,81^{p}$ \\
Scopoletin & $76,61 \pm 7,17$ & $52,60 \pm 20,16$ & $65,10 \pm 20,16 q$ \\
Tempol & $68,25 \pm 15,93$ & $74,43 \pm 0,70$ & $71,34 \pm 9,87 q$ \\
\hline
\end{tabular}

NO: serum concentration of nitric oxide; $\mathrm{PN}$ : group treated with prednisone $+\mathrm{NaCl}$; PNL: group treated with prednisone $+\mathrm{NaCl}+\mathrm{L}-\mathrm{NAME} ;(\mathrm{n}=18)$.

Data are expressed as mean of percent change \pm SEM. Different superscript indicates significant difference at $95 \%$ confidence interval (post hoc analysis by Tukey's HSD)

\section{DISCUSSION}

Scopoletin (Figure 1A, IR spectrum is shown in Figure 2) is a coumarin derivative compound which is usually found in higher plants. Within the last decade, several pharmacological activities of scopoletin that may contribute to lowering elevated blood pressure have been reported. The most closely related pharmacological effects are vasorelaxant and hypotensive activities from the extracts containing scopoletin [12-14]. Hence, further investigation on the scopoletin effect as a single compound to lower the blood pressure is necessary to be conducted in animal models. The use of multiple models of hypertensive animals is strongly suggested to mimic the pathological condition of hypertension in a human being since it is believed to be a complex and multifactorial disease [21,22].

The most significant finding from the present study is that scopoletin exhibits a blood pressure lowering effect in hypertensive rats. The compound reduced the systolic (SBP) and diastolic blood pressure (DBP), and mean arterial pressure (MAP). Table 2 shows that scopoletin exerts its antihypertensive effect without significantly influencing the heart rate (HR). When compared with tempol, a well-known antioxidant, scopoletin caused a better blood pressure lowering effect. In addition, the treatment of scopoletin also decreased all blood pressure parameters over time during 120 minutes of observation (Table 3). Interestingly, this hypotensive effect improved significantly in oxidative stress-associated hypertensive animals (PNL group). Comparative effect of all doses for all blood pressure parameters demonstrated in Table 4 shows a significant antihypertensive effect in oxidative stress hypertension (PNL group) as compared with general hypertension (PN group).

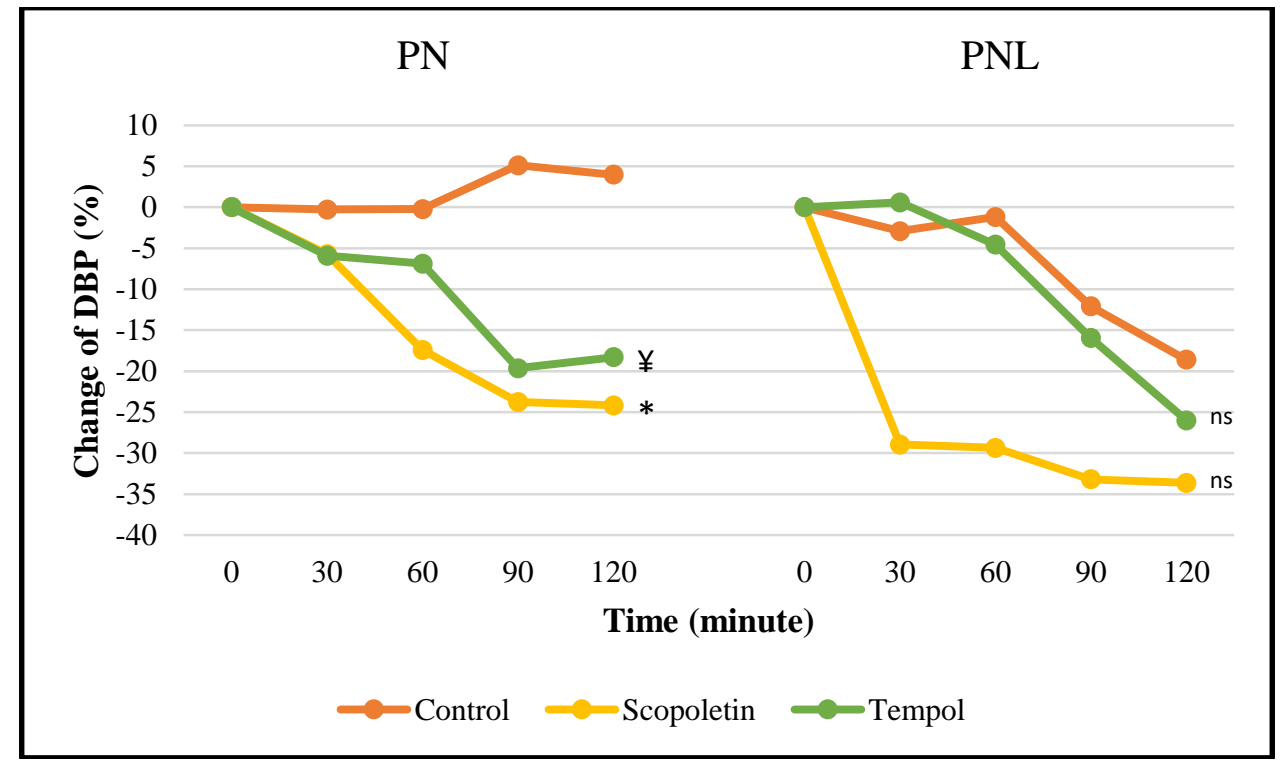

Figure 3. Comparative effect of the treatment to DBP (diastolic blood pressure) on different hypertensive models during 120 minutes of observation $(\mathrm{PN}=$ group treated with prednisone $+\mathrm{NaCl} ; \mathrm{PNL}=$ group treated with prednisone $+\mathrm{NaCl}+\mathrm{L}-\mathrm{NAME}$; data with negative $(-)$ values indicate the decrease of the parameter; ${ }^{*} \mathrm{p}<0.05, ¥ 0.05<\mathrm{p}<0.1$, and $\mathrm{ns}=$ not significant comparative to control; $\mathrm{n}=18$ ). 
The use of the direct method of blood pressure measurement has been suggested as the gold standard since it provides a straight indication to the circulatory system and beat-to-beat information with more accuracy. This intra-arterial monitoring was used in the present study by directly inserting a saline-filled catheter into the carotid artery. Although this method is invasive and may cause fluctuation due to anesthesia, it is still considered as a good choice to investigate the vascular reaction to several test compounds, such as scopoletin and tempol that were investigated in this study $[23,24]$.

To study hypertension in experimental animals, a number of models have been introduced. The use of multiple models in investigating the blood pressure lowering effect of a test compound or plant extract is necessary to represent several pathological conditions of human hypertension for in vivo investigation. A combination of prednisone and $\mathrm{NaCl}$ has been used in some investigational studies for plant extract $[25,26]$. This model of hypertension is comparable to major types of clinical hypertension in human, mainly the primary aldosteronism and chronic high salt intake hypertension [21]. The addition of $\mathrm{N}^{\omega}{ }^{\omega}$-nitro-L-arginine methyl ester (L-NAME) may cause endothelial dysfunction due to inhibition of endothelial nitric oxide synthase (eNOS) enzyme. This leads to decreased capacity of endothelium-derived relaxing factor (EDRF) and causes overproduction of reactive oxygen species (ROS), a condition known as oxidative stress [20]. This condition is similar with those reported by several researcher [27-29].

Furthermore, the inhibition in the synthesis or bioavailability of nitric oxide (NO) has an important role in the progress of hypertension. The condion caused by L-NAME induced hypertension is similar to that due to the blocking of endothelial nitric oxide synthase (eNOS) activity [30]. However, the present data shows no significant difference on the NO concentration between two groups (PN and PNL) despite the serum cocentration of NO in PNL animal is slightly lower. The baseline values of NO concentration in both PN and PNL groups are comparable as demonstrated by Figure 6. This phenomenon was also observed in our previous study [26]. It means that L-NAME could not further induce oxidative stress since hypertensive condition induced by salt-prednison itself is similar with that induced by DOCA-salt [31] and Dahl-salt sensitive hypertensive rats [32] that has already in the oxidative stress condition.

Table 3. Effect of the treatment to blood pressures and heart rate during 120 minutes of observation.

\begin{tabular}{|c|c|c|c|c|c|}
\hline \multirow[t]{2}{*}{ Doses } & \multicolumn{5}{|c|}{ Percent change of parameters over time (\%) } \\
\hline & $0^{\prime}$ & $30^{\prime}$ & $60^{\prime}$ & $90^{\prime}$ & $120^{\prime}$ \\
\hline \multicolumn{6}{|c|}{ Systolic blood pressure (SBP) } \\
\hline Control & $0 \pm 2.55$ & $-1.85 \pm 2.55$ & $2.16 \pm 2.55$ & $-6.84 \pm 2.55$ & $-13.98 \pm 2.55$ \\
\hline Scopoletin & $0 \pm 2.55$ & $-19.57 \pm 2.55$ & $-21.82 \pm 2.55$ & $-25.92 \pm 2.55$ & $-27.86 \pm 2.55$ \\
\hline Tempol & $0 \pm 2.55$ & $-2.95 \pm 2.55$ & $-5.01 \pm 2.55$ & $-12.91 \pm 2.55$ & $-14.75 \pm 2.55$ \\
\hline \multicolumn{6}{|c|}{ Diastolic blood pressure (DBP) } \\
\hline Control & $0 \pm 3.56$ & $-1.6 \pm 3.56$ & $-0.71 \pm 3.56$ & $-3.5 \pm 3.56$ & $-7.31 \pm 3.56$ \\
\hline Scopoletin & $0 \pm 3.56$ & $-17.34 \pm 3.56$ & $-23.39 \pm 3.56$ & $-28.49 \pm 3.56$ & $-28.9 \pm 3.56$ \\
\hline Tempol & $0 \pm 3.56$ & $-2.67 \pm 3.56$ & $-5.73 \pm 3.56$ & $-17.82 \pm 3.56$ & $-22.17 \pm 3.56$ \\
\hline \multicolumn{6}{|c|}{ Mean arterial pressure (MAP) } \\
\hline Control & $0 \pm 6.13$ & $-3.34 \pm 6.13$ & $4.37 \pm 6.13$ & $-4.51 \pm 6.13$ & $-13 \pm 6.13$ \\
\hline Scopoletin & $0 \pm 6.13$ & $-45.61 \pm 6.13$ & $-49.79 \pm 6.13$ & $-59.27 \pm 6.13$ & $-61.97 \pm 6.13$ \\
\hline Tempol & $0 \pm 6.13$ & $-5.95 \pm 6.13$ & $-9.75 \pm 6.13$ & $-38.17 \pm 6.13$ & $-38.5 \pm 6.13$ \\
\hline \multicolumn{6}{|c|}{ Heart rate (HR) } \\
\hline Control & $0 \pm 3.00$ & $5.47 \pm 3.00$ & $3.96 \pm 3.00$ & $-2.63 \pm 3.00$ & $-0.93 \pm 3.00$ \\
\hline Scopoletin & $0 \pm 3.00$ & $-3.67 \pm 3.00$ & $-1.19 \pm 3.00$ & $1.55 \pm 3.00$ & $2.26 \pm 3.00$ \\
\hline Tempol & $0 \pm 3.00$ & $-7.67 \pm 3.00$ & $-2.142 \pm 3.00$ & $-2.19 \pm 3.00$ & $-4.98 \pm 3.00$ \\
\hline
\end{tabular}

SBP: systolic blood pressure; DBP: diastolic blood pressure; MAP: mean arterial pressure; HR: heart rate; $(n=18)$. Data are expressed as mean of percent change \pm SEM. Negative $(-)$ values indicate the decrease of parameters. Different superscript within the row average indicates significant difference at $95 \%$ confidence interval (post hoc analysis by Tukey's HSD). 
The administration of L-NAME leads to a significant increase in blood pressure. L-NAME-induced hypertension is also associated with an upregulation of some major antioxidants that include superoxide dismutase (SOD), glutathione peroxidase (GPX), and glutathione reductase (GR) activities [33]. These characteristics are strong indicators of oxidative stress in the cardiovascular system leading to elevated blood pressure [34]. Nevertheless, the present study also showed a significant increase of blood pressure in animals treated with L-NAME that confirmed the previous study [26].

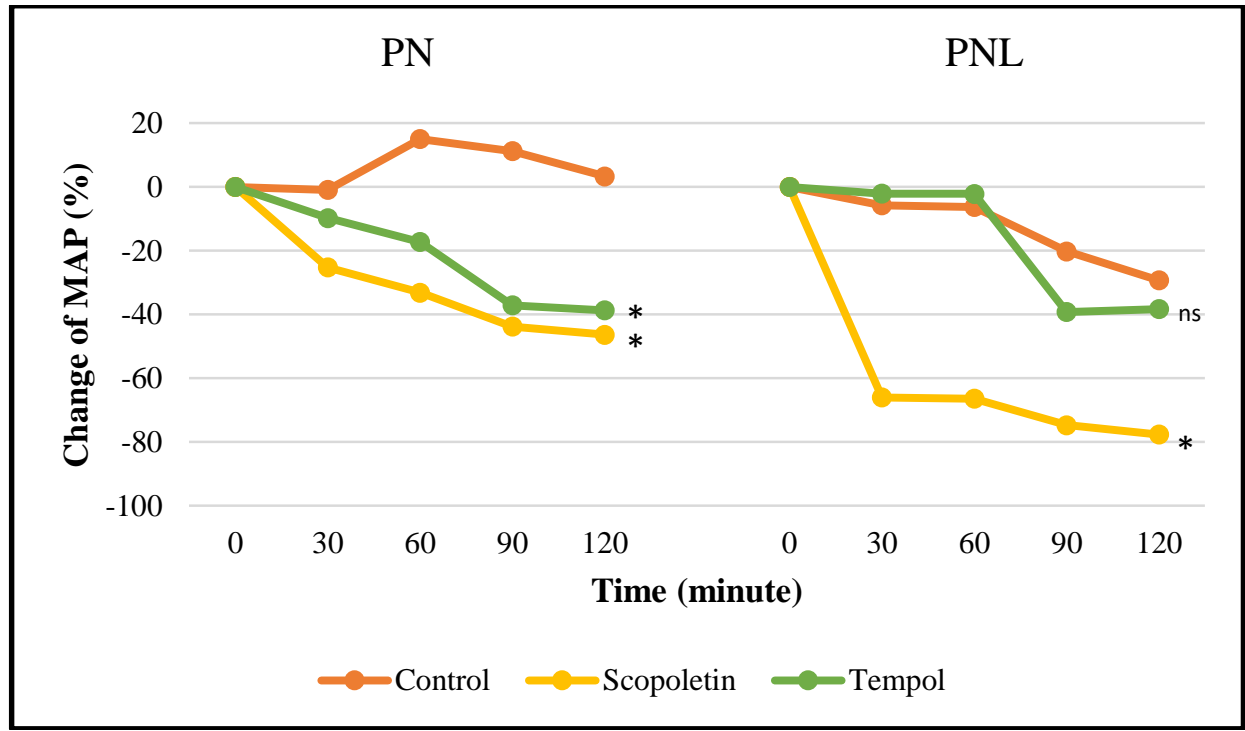

Figure 4. Comparative effect of the treatment to MAP (mean arterial pressure) on different hypertensive models during 120 minutes of observation $(\mathrm{PN}=$ group treated with prednisone $+\mathrm{NaCl} ; \mathrm{PNL}=$ group treated with prednisone $+\mathrm{NaCl}+\mathrm{L}-\mathrm{NAME}$; data with negative (-) values indicate the decrease of the parameter; ${ }^{*} \mathrm{p}<0.05$ and $\mathrm{ns}=$ not significant comparative to control; $\mathrm{n}=18$ ).

Tempol (4-hydroxy TEMPO, Figure 1B) is a nitroxide antioxidant which is considered among the most potent antioxidants in protecting the tissue from oxidative stress due to increased bioavailability of reactive oxygen species (ROS). Tempol exhibits a superoxide dismutase (SOD)-mimic activity and has shown a protective effect in many disorders associated with oxidative stress, including hypertension. The blood pressure lowering effect of tempol has long been reported in several animal models of hypertension $[19,35,36]$.

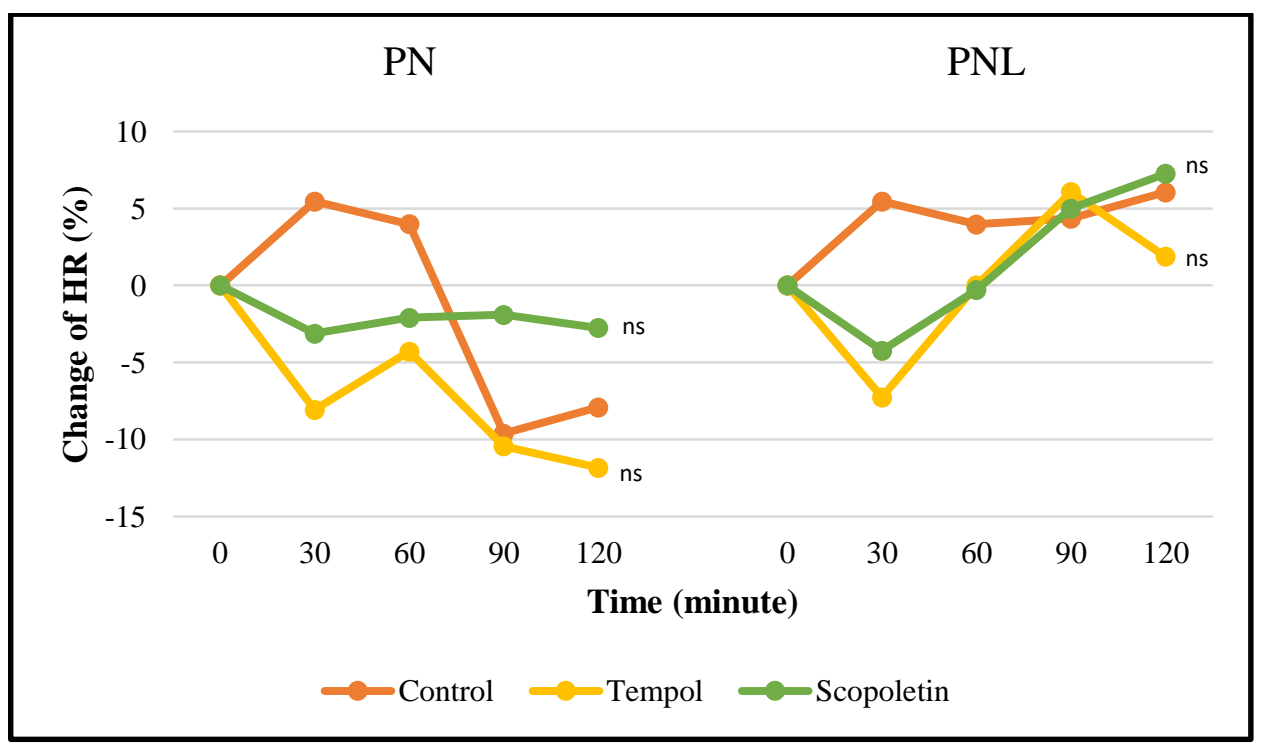

Figure 5. Comparative effect of the treatment to HR (heart rate) on different hypertensive models during 120 minutes of observation $(\mathrm{PN}=$ group treated with prednisone $+\mathrm{NaCl}$; PNL $=$ group treated with prednisone $+\mathrm{NaCl}+\mathrm{L}-\mathrm{NAME}$; data with negative $(-)$ values indicate the decrease of the parameter; $\mathrm{ns}=$ not significant comparative to control; $\mathrm{n}=18$ ). 
Herein, the use of tempol as a comparator was to be associated with the antioxidant capacity of scopoletin and the serum concentration of nitric oxide (NO). The result showed that the blood pressure lowering effect of these two compounds were mostly significant compared with control. Interestingly, scopoletin often caused a better effect than tempol in decreasing the blood pressure (Table 2). However, the raw recording data showed that tempol lowered the blood pressure in a more stable manner, despite the use of direct invasive measurement caused fluctuation in blood pressure parameters.

The study showed that the serum concentration of nitric oxide (NO) increased in all treatment and groups, contrary to the effect on the blood pressure. Although both animal models showed comparable nitric oxide concentration, the PNL groups that received additional L-NAME administration was likely to be more responsive to the blood pressure lowering effect of scopoletin and tempol. Table 4 shows that the antihypertensive activity of these substances are significantly greater in PNL group, despite the equal concentration of NO compared with PN group. This phenomenon suggests that the oxidative stress not only influences the nitric oxide metabolism but may also affect other biochemical processes that contribute to the vascular function. Previous studies have reported that the administration of L-NAME increases the blood pressure along with some markers of oxidative stress in cardiac and renal tissues, organs that play a major role in controlling the blood pressure. Several biochemical processes such as catalase activity and lipid peroxidation are also altered. These processes may serve as alternative pathway in the metabolism of nitric oxide $[37,38]$. Therefore, the restoration of antioxidant capacity due to the administration of scopoletin and tempol may induce a better blood pressure lowering effect in the oxidative stress-associated hypertensive model.

Table 4. Comparative effect of the treatment to blood pressures and heart rate in PN \& PNL hypertensive groups

\begin{tabular}{lcccccccc}
\hline Doses & \multicolumn{2}{c}{ SBP } & \multicolumn{2}{c}{ DBP } & \multicolumn{2}{c}{ MAP } & \multicolumn{2}{c}{ HR } \\
\cline { 2 - 9 } & PN & PNL & PN & PNL & PN & PNL & PN & PNL \\
\hline Control & 2.72 & -10.93 & 1.72 & -6.97 & 5.73 & -12.32 & -1.65 & 3.97 \\
Scopoletin & -14.16 & -25.03 & -14.22 & -25.03 & -29.70 & -56.96 & -1.97 & 1.55 \\
Tempol & -7.74 & -6.49 & -10.15 & -9.17 & -20.57 & -16.38 & -6.93 & 0.14 \\
\hline
\end{tabular}

SBP: systolic blood pressure; DBP: diastolic blood pressure; MAP: mean arterial pressure; HR: heart rate; PN: group treated with prednisone $+\mathrm{NaCl}$; PNL: group treated with prednisone $+\mathrm{NaCl}+\mathrm{L}-\mathrm{NAME} ;(\mathrm{n}=18)$.

Data are expressed as mean of percent change \pm SEM. Negative (-) values indicate the decrease of parameters.

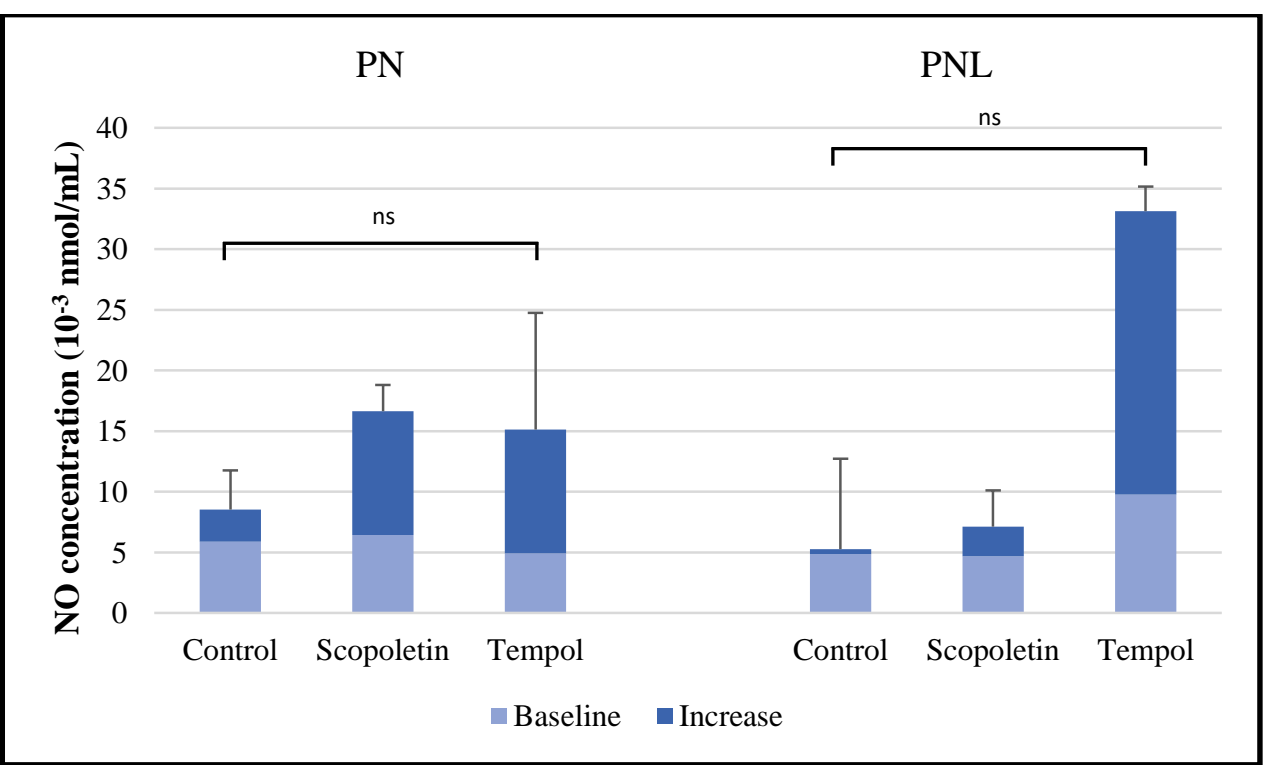

Figure 6. Comparative effect of the treatment to the increase of serum concentration of nitric oxide (NO) on different hypertensive models $(\mathrm{PN}=$ group treated with prednisone $+\mathrm{NaCl}$; $\mathrm{PNL}=$ group treated with prednisone $+\mathrm{NaCl}+\mathrm{L}-\mathrm{NAME} ; \mathrm{n}=18)$. 
The dose of scopoletin used in this study was $10 \mathrm{mg} / \mathrm{kg}$. This was based on the thought that amount of pure compound used to perform in vivo study may be started with such a small dose [39]. Nonetheless, this dose was able to decrease the blood pressure and was better than that by tempol. The effect became significant in 90 to 120 minutes after drug commencement. This phenomenon was referred to scopoletin pharmacokinetic profile reported to reach the peak level in two hours after administered intravenously. Scopoletin was also reported to exhibit non-linear pharmacokinetics when administered intravenously in the dose of $2-50 \mathrm{mg} / \mathrm{kg}$. This was also the reason to carry out a single dose of $10 \mathrm{mg} / \mathrm{kg}$ scopoletin after the rats had been settled in the acute operative procedure $[6,40]$.

\section{CONCLUSION}

In conclusion, the study suggests that scopoletin is a potent antihypertensive agent that exhibits significant reduction of systolic blood pressure, diastolic blood pressure, and mean arterial pressure without producing any significant effect on the heart rate. The blood pressure lowering effect of scopoletin is significant in oxidative stress animal model of hypertension.

\section{MATERIALS AND METHODS}

\subsection{Drug and chemicals}

Scopoletin compound was purchased from Sumatran Biota Laboratory, lot no. 1408007 (Andalas University, Indonesia). Prednisone was obtained from a local pharmacy. $\mathrm{N}^{\omega}$-nitro-L-arginine methyl ester (LNAME) and tempol (4-hydroxy TEMPO) were purchased from Sigma-Aldrich (Sigma-Aldrich Corp., USA). Heparin and $\mathrm{NaCl}$ 0.9\% intravenous infusion were products of BBraun (Indonesia). Nitric oxide colorimetric assay kit (Cat. K262-200, Lot. 80762) was purchased from BioVision (BioVision Inc., USA).

\subsection{Animal preparation}

A number of 18 adult male Wistar-Kyoto rats (weighed $\pm 250 \mathrm{~g}$ and aged 2-3 months old) were acclimatized to normal laboratory condition with 12:12 light/dark cycles for 7 days and provided standard chow and water ad libitum. The animals were divided into 2 groups: a half of the animals were induced with prednisone $1.5 \mathrm{mg} / \mathrm{kg}$ in combination with salt solution $2.5 \%$ for 14 days (PN group), while another half were treated similarly, but with additional oral administration of $N^{\omega}$-nitro-L-arginine methyl ester (L-NAME) 20 $\mathrm{mg} / \mathrm{kg}$ in the last two days (PNL group). Hypertension was indicated if the mean arterial pressure of the rat $>150 \mathrm{mmHg}$. This method was a slight modification of our previous study [26]. All protocols have been approved by the ethics committee of Andalas University (042/KEP/FK/2015).

\subsection{Antihypertensive activity evaluation}

The rats were anesthetized with propofol $150 \mathrm{mg} / \mathrm{kg}$ administered intraperitoneally and placed on a suitable rodent surgical table. The rat's skin on the ventral side of the neck, right hind leg, and chest were carefully shaved and disinfected. The arterial blood pressure was measured directly from right carotid artery via an arterial cannula connected to a pressure transducer coupled with a hemodynamic recorder (Biopac MP 150, USA). The left jugular vein was cannulated with PP 50 tubing to allow scopoletin administration and supplementary infusion of propofol $4 \%$. The rats were divided into three groups receiving vehicle control; scopoletin $10 \mathrm{mg} / \mathrm{kg}$; and tempol $100 \mu \mathrm{mol} / \mathrm{kg}$. The doses were administered intravenously after the blood pressure stabilized for 60 minutes. Systolic blood pressure (SBP), diastolic blood pressure (DBP), mean arterial pressure (MAP) and heart rate (HR) were recorded during 120 minutes of observation. The experiment was conducted in triplicates and all parameters were calculated as percentage changes relative to baseline values.

\subsection{Nitric oxide concentration measurement}

The blood was collected before drug administration and at the end of the experiment through the carotid artery. The blood was centrifuged for 15 minutes at $4000 \mathrm{rpm}$ to obtain the serum and stored at $-20{ }^{\circ} \mathrm{C}$ for further measurement. The NO concentration was determined by spectrophotometer (BioRad Lab Inc., USA) by using enzyme-linked immunosorbent assay (ELISA) method (BioVision Inc., USA).

\subsection{Data Analysis}

Data were presented as mean of percent change \pm standard error of mean (SEM). All data from the experiment were analyzed using two-way analysis of variance (ANOVA). Significant differences were 
followed by Tukey's HSD (Honestly Significant Difference). The significance level was taken at 95\% confidence interval. All statistical analyses were conducted by using SPSS version 19 for Windows.

Author contributions: Concept - A.A., Y.Y.; Design - A.A., Y.Y.; Supervision - A.A., Y.Y.; Resources - A.A., R.H., M.M.; Materials - A.A., R.H., M.M.; Data Collection and/or Processing - A.A., R.H., M.M., Y.Y.; Analysis and/or Interpretation - A.A., R.H., M.M., Y.Y.; Literature Search - A.A., R.H., M.M., Y.Y.; Writing - A.A., Y.Y.; Critical Reviews - A.A., R.H., M.M., Y.Y.

Conflict of interest statement: The authors declared no conflict of interest.

\section{REFERENCES}

[1] Poulter NR, Prabhakaran D, Caulfield M. Hypertension. Lancet. 2015;386(9995):801-812. [CrossRef]

[2] WHO. World Health Organization, Hypertension. World Health Organization. http://www.searo.who.int/topics/hypertension/en/. Published 2017. Accessed September 29, 2017.

[3] Hussain MA, Al Mamun A, Reid C, Huxley RR. Prevalence, awareness, treatment and control of hypertension in Indonesian adults aged $\geq 40$ years: Findings from the Indonesia Family Life Survey (IFLS). PLoS One. 2016;11(8):e0160922. [CrossRef]

[4] Gnonlonfin GJB, Sanni A, Brimer L. Review scopoletin - A coumarin phytoalexin with medicinal properties. CRC Crit Rev Plant Sci. 2012;31(1):47-56. [CrossRef]

[5] Asif M. Pharmacological activities and phytochemistry of various plant containing coumarin derivatives. Curr Sci Perspect. 2015;1(3):77-90.

[6] Mahadeva Rao US, Mohd KS, Atif AB, Latif AZBA. Scopoletin (coumarin extracted from Mengkudu): Chemical, biological, molecular and pharmacokinetic insights - A review. Res J Pharm Technol. 2013;6(9):978-984.

[7] Pereira dos Santos Nascimento MV, Arruda-Silva F, Gobbo Luz AB, Baratto B, Venzke D, Mendes BG, Fröde TS, Geraldo Pizzolatti M, Dalmarco EM. Inhibition of the NF-kB and p38 MAPK pathways by scopoletin reduce the inflammation caused by carrageenan in the mouse model of pleurisy. Immunopharmacol Immunotoxicol. 2016;38(5):344-352. [CrossRef]

[8] Shi W, Hu J, Bao N, Li D, Chen L, Sun J. Design, synthesis and cytotoxic activities of scopoletin-isoxazole and scopoletin-pyrazole hybrids. Bioorganic Med Chem Lett. 2017;27(2):147-151. [CrossRef]

[9] Malik A, Kushnoor A, Saini V, Singhal S, Kumar S, Yadav YC. In vitro antioxidant properties of Scopoletin. J Chem Pharm Res. 2011;3(3):659-665.

[10] Mogana R, Teng-Jin K, Wiart C. Anti-inflammatory, anticholinesterase, and antioxidant potential of scopoletin isolated from Canarium patentinervium Miq. (Burseraceae Kunth). Evidence-based Complement Altern Med. 2013;2013. [CrossRef]

[11] Shaw CY, Chen CH, Hsu CC, Chen CC, Tsai YC. Antioxidant properties of scopoletin isolated from Sinomonium acutum. Phytother Res. 2003;17(7):823-825. [CrossRef]

[12] Guantai AN, Addae-Mensah I. Cardiovascular effect of Artemisia afra and its constituents. Pharm Biol. 1999;37(5):351356. [CrossRef]

[13] Iizuka T, Nagumo S, Yotsumoto H, Moriyama H, Nagai M. Vasorelaxant effects of Acer nikoense extract and isolated coumarinolignans on rat aortic rings. Biol Pharm Bull. 2007;30(6):1164-1166. [CrossRef]

[14] Wigati D, Anwar K, Sudarsono, Nugroho AE. Hypotensive activity of ethanolic extracts of Morinda citrifolia L. leaves and fruit in dexamethasone-induced hypertensive rat. J Evid Based Complementary Altern Med. 2017;22(1):107-113. [CrossRef]

[15] Akpaffiong MJ, Taylor AA. Antihypertensive and vasodilator actions of antioxidants in spontaneously hypertensive rats. Am J Hypertens. 1998;11(12):1450-1460. [CrossRef]

[16] Galley HF, Thornton J, Howdle PD, Walker BE, Webster NR. Combination oral antioxidant supplementation reduces blood pressure. Clin Sci. 1997;92(4):361-365.

[17] Ye Y, Li J, Yuan Z. Effect of antioxidant vitamin supplementation on cardiovascular outcomes: A Meta-analysis of randomized controlled trials. PLoS One. 2013;8(2):e56803. [CrossRef]

[18] Yanai H, Ito K, Yoshida H, Tada N. Antihypertensive effects of astaxanthin. Integr Blood Press Control. 2008;1(2005):1-3. [CrossRef]

[19] Wilcox CS, Pearlman A. Chemistry and antihypertensive effects of tempol and other nitroxides. Pharmacol Rev. 
2008;60(4):418-469. [CrossRef]

[20] Schulz E, Gori T, Münzel T. Oxidative stress and endothelial dysfunction in hypertension. Hypertens Res. 2011;34(6):665-673. [CrossRef]

[21] Badyal DK, Lata H, Dadhich AP. Animal models of hypertension and effect of drugs. Indian J Pharmacol. 2003;35:349362.

[22] Dornas WC, Silva ME. Animal models for the study of arterial hypertension. J Biosci. 2011;36(4):731-737. [CrossRef]

[23] Parasuraman S, Raveendran R. Measurement of invasive blood pressure in rats. J Pharmacol Pharmacother. 2012;3(2):172-177.

[24] Ward M, Langton JA. Blood pressure measurement. Contin Educ Anaesthesia, Crit Care Pain. 2007;7(4):122-126. [CrossRef]

[25] Armenia A, Yuliandra Y, Sattar MZA. Comparative effectiveness of defatted hypotensive crude extract, ethyl acetate and butanolic fractions of Cassytha filiformis L. on different models of hypertensive rats. World J Pharm Pharm Sci. 2014;3(12):200-208

[26] Yuliandra Y, Armenia A, Arifin H. Antihypertensive and antioxidant activity of Cassytha filiformis L.: A correlative study. Asian Pac J Trop Biomed. 2017;7(7):614-618. [CrossRef]

[27] McIntyre M, Bohr DF, Dominiczak AF. Endothelial function in hypertension: The role of superoxide anion. Hypertension. 1999;34(4 I):539-545. [CrossRef]

[28] Ballinger SW, Patterson C, Yan CN, Doan R, Burow DL, Young CG, Yakes FM, Van Houten B, Ballinger CA Freeman BA, Runge MS. Hydrogen peroxide- and peroxynitrite-induced mitochondrial DNA damage and dysfunction in vascular endothelial and smooth muscle cells. Circ Res 2000;86(9):960-966. [CrossRef]

[29] Spieker LE, Noll G, Ruschitzka FT, Maier W, Luscher TF. Working under pressure: The vascular endothelium in arterial hypertension. J Hum Hypertens. 2000;14(10-11):617-630. [CrossRef]

[30] Talas ZS, Ozdemir I, Ciftci O, Cakir O, Gulhan MF, Pasaoglu OM. Role of propolis on biochemical parameters in kidney and heart tissues against L-NAME induced oxidative injury in rats. Clin Exp Hypertens. 2014;36(7):492-496. [CrossRef]

[31] Iyer A, Chan V, Brown L. The DOCA-salt hypertensive rat as a model of cardiovascular oxidative and inflammatory stress. Curr Cardiol Rev 2010;6(4):291-297. [CrossRef]

[32] Meng S, Cason GW, Gannon AW, Racusen LC, Manning RD. Oxidative stress in Dahl salt-sensitive hypertension. Hypertension 2003;41(6):1346-1352. [CrossRef]

[33] Sainz J, Wangensteen R, Gómez IR, Moreno JM, Chamorro V, Osuna A, Bueno P, Vargas F. Antioxidant enzymes and effects of tempol on the development of hypertension induced by nitric oxide inhibition. Am J Hypertens. 2005;18(6):871-877. [CrossRef]

[34] Cosentino F, Christopher Sill J, Katušić ZS. Role of superoxide anions in the mediation of endothelium-dependent contractions. Hypertension. 1994;23(2):229-235. [CrossRef]

[35] Beigrezaei S, Nasri H. Tempol as an antioxidant; an updated review on current knowledge. Ann Res Antioxidants. 2017;2(1):e01.

[36] Dornas WC, Silva M, Tavares R, De Lima WG, Dos Santos RC, Pedrosa ML, Silva ME. Efficacy of the superoxide dismutase mimetic tempol in animal hypertension models: a meta-analysis. J Hypertens. 2015;33(1):14-23. [CrossRef]

[37] Adaramoye O, Farombi E, Nwosu I. Sub-acute effect of NG-nitro-l-arginine methyl-ester (L-NAME) on biochemical indices ins rats: Protective effects of Kolaviron and extract of Curcuma longa L. Pharmacognosy Res. 2012;4(3):127. [CrossRef]

[38] Alp Yildirim FI, Eker Kizilay D, Ergin B, Balci Ekmekçi O, Topal G, Kucur M, Demirci Tansel C, Uydeş Dołan BS. Barnidipine ameliorates the vascular and renal injury in 1-NAME-induced hypertensive rats. Eur J Pharmacol. 2015;764:433-442. [CrossRef]

[39] Hock FJ, ed. Drug Discovery and Evaluation: Pharmacological Assays. 4th ed. Springer International Publishing; 2015. [CrossRef]

[40] Liu SL, Hsieh MT, Liu CH. Pharmacokinetics of scopoletin after intravenous administration in rabbits. Chinese Pharm J. 1999;51(4):245-254. 